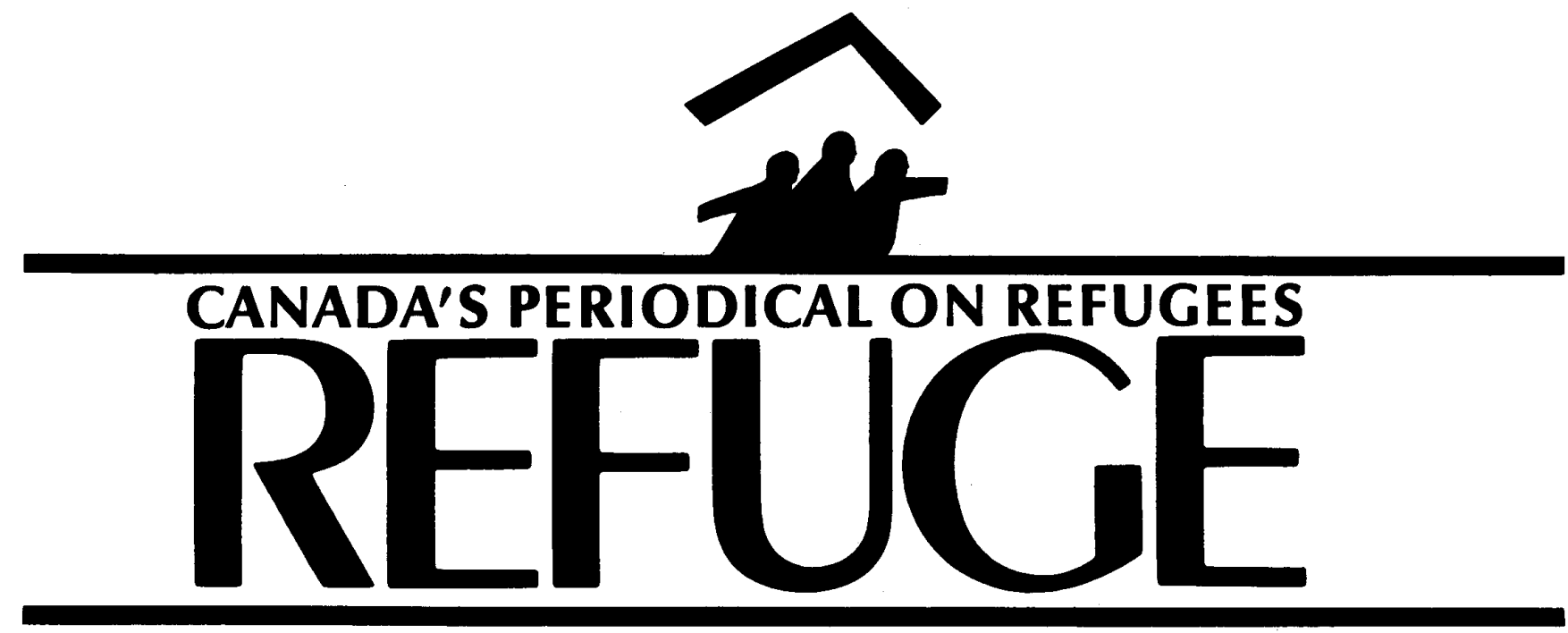

Vol. 10, No. 2

December 1990

\title{
Refugees and Literacy
}

Literacy refers, in its most narrow sense, to an ability to read and write. But literacy also entails, in a broader and much more rewarding sense, being able to effectively put these acquired skills to use in daily life. Only when we become functionally literate do we start reaping in earnest the practical rewards of learning.

These rewards can be quite substantial. Literacy can help us satisfy our basic needs or boost our self-esteem. It could even facilitate individual and communal quests for integration and, most importantly, for empowerment.

The achievement of functional literacy, a challenge to native speakers, becomes a monumental task for those who, like most refugees, generally do not master any of the common languages of the countries where they resettle.

Not surprisingly, the lack of mastery over a common language is widely perceived to be the most frustrating limitation faced by those trying to adapt to a new environment. This added limitation only compounds the social and cultural traumas experienced by refugees.

Ideally speaking, literacy programs available to unwilling migrants such as refugees should cater to their specific needs. These needs differ substantially from those of other immigrants who willingly move to another country.

In Canada seldom do basic schooling, adult education or mother tongue literacy programs take into consideration refugee requirements. More often than not refugees are limited to taking advantage of standard English as a Second Language (ESL) or français langue seconde programs available to all immigrants.

The articles contained in the present issue are illustrations of Canada's current refugee literacy debate. The authors are all practitioners in the field of

education who work with refugees in different parts of the country. From different perspectives they discuss the literacy challenges refugees have to face, describe the available facilities, assess some of the advances being made, identify prevailing problems and suggest ways ot overcome them in order to improve the literacy programs now available in Canada to refugees.

Marlinda Freire approaches the issue of ESL and literacy programs from a psycho-emotional perspective. She emphasizes the importance of early attendance: 'Learning may not take place

Continued on page 2

\section{IN THIS ISSUE:}

Refugees: ESL and Literacy by Marlinda Freire page 3

Intégration à la société québécoise par l'apprentissage de la langue par Marie-Françoise Fayolle

Some Thoughts Concerning the Education of Refugee Children by Marcela Durán

page 10

Literacy for the Health of Refugees - Broadly Speaking by Ann Goldblatt

page 14

The Commonwealth of Literacy:

Literacy, Distance Education and Refugees 
initially (or may be minimal). This early experience may be of tremendous value in helping refugees to regain some of 'the self,' with learning taking place later on." ESL courses and literacy programs are nevertheless only part of the solution. Marlinda Freire underlines the enormous difficulties in dealing with the complex problems affecting refugees in general and refugee children in particular, and points out the need for more elaborate efforts stemming from a more all-encompassing approach.

Marie-Françoise Fayolle discusses

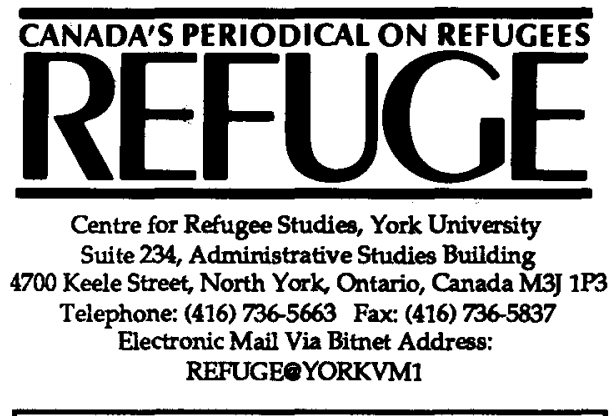

Guest Editor:

Alex Zisman

Editor:

Howard Adelman

Illustrations:

Herminio Ordóñez

Circulation Manager:

Helen Gross

Assistant to the Circulation Manager: Ching Man (C.M.) Wong

Refuge is dedicated to the encouragement of assistance to refugees by providing a forum for sharing information and opinion on Canadian and international issues pertaining to refugees. It is published four times a year by the Centre for Refugee Studies. It is a non-profit, independent periodical supported by private donations and by subscriptions. It is a forum for discussion, and the views expressed do not necessarily reflect those of its funders or staff.

All materials in Refuge may be reproduced without permission unless copyrighted or otherwise indicated. Credit should be given to the author or source, if named.

Subscription rates for one year are $\$ 20.00$ in Canada and US $\$ 25.00$ overseas. Please enclose payment with your order.

Logo design:

Dreadnaught Co-operative Inc., Toronto

Second Clase Mail Regitutration No. 5512 ISSN 0229-5113 language learning as a form of integration in francophone Québec. Not unlike Marlinda Freire her focus is mainly on the effect of literacy programs, but in a French-speaking context. Perhaps the most serious problem refugee claimants must face in Québec is the limited access to language classes and rewarding communal activities available to other immigrants. This also contributes to hamper even further francophone integration efforts already undermined by such threats as the predominant use of English in neighbourhoods and at the workplace. Yet, as Fayolle seems to indicate, there are enough grounds to believe that the widespread implementation of clear outreach policies can ensure an effective functional and just integration of even the first generation of new immigrants in Québec.

Marcela Durán's focus on the education of refugee children reveals changing patterns of criteria for school placement and policies related to minority groups since World War II. She credits multicultural policies for bringing about a sense of acceptance of ethnicity and differences in the schools over the past 30 years. This change led also to the creation of Heritage Language programs and the implementation of Race Relations policies. There has certainly been a great improvement in awareness and acceptance of problem-solving policies in the school system over the past decades, but concern still remains for the uneven delivery of services and facilities available at schools. Durán pinpoints in more detail problem areas regarding the education of refugee children. Areas such as reception, assessment and classroom-teacher training ought to be improved. Faster changes in immigrant and refugee education at teacher-training institutions should also be implemented.

Ann Goldblatt uses her Edmonton data to compare the way health and refugee workers have put their mandates into practice. She touches upon the "adjustment experience" of refugees and considers the broader notion of literacy as education for social justice. Like the other contributors, she finds inspiration in the precepts of Paulo Freire (particularly in his notion of "liberation literacy") as she examines and questions the mandates of second language educators, agency-based refugee workers and health workers dealing with refugees, and defines some strategies for change based on the orientation of those who have come through the refugee experience.

One of the difficultires refugee experts must confront in Canada is the limited number of opportunities to implement valuable participatory research policies related to refugees and literacy. We were able to take advantage of the input of some of these experts at a recent seminar organized by the Centre for Refugee Studies on literacy, distance education and refugees. As the edited minutes of the seminar attest, the open exchange of information helped define the initial parameters of a possible distance education, literacy and literacy training program for Mozambican refugees in Southern Africa, to be sponsored by The Commonwealth of Learning under the coordination of Flora MacDonald.

International Literacy Year may be coming to an end, but the lasting legacy and resourcefulness of improving literacy projects in Canada and around the world continues to prevail.

Alex Zisman, Guest Editor

\section{Acknowledgements}

The publication of this special issue on refugees and literacy has been made possible by the ongoing financial support of Employment and Immigration Canada and special funding provided by the National Literacy Secretariat, Department of Secretary of State, through the auspicies of Richard Nolan, its Director General.

The opinions expressed in the articles and in the edited minutes of the seminar are, respectively, those of the authors and participants and are not necessarily those of the funders. 